\title{
Laparoscopic Rectal Cancer Surgery: A Pan-Canadian Analysis
}

\section{Ashley Drohan ${ }^{1,2}$ MD, Marius Hoogerboord ${ }^{1}$ MD FRCSC FACS}

Paul Johnson ${ }^{1}$ MD FRCSC, Gordon Flowerdew ${ }^{2}$ MSc DSc and Geoff Porter ${ }^{1,2}$ MD FRCSC FACS

1- Department of Surgery, Dalhousie University, Halifax, NS

2- Department of Community Health and Epidemiology, Dalhousie University, Halifax NS

\section{Introduction}

- Over the past decade, randomized controlled trials have demonstrated non-inferior oncologic outcomes in rectal cancer patients who undergo laparoscopic surgery (LS) when compared to those who undergo open surgery (OS).

- MRC-CLASICC ${ }^{1,2}$, COREAN $^{3}$ and COLOR $\|^{4}$ found no difference in survival and local recurrence between LS and OS and improved short-term outcomes with LS.

- Some concern remains with LS for rectal cancer regarding inferior pathological endpoints observed in more recent randomized controlled trials ${ }^{5,6}$.

- Currently, there is a lack of Canadian data on the uptake of LS for rectal cancer.

\section{Purpose}

To describe the national and provincial use of LS for rectal cancer in Canada, and to identify factors associated with its use.

\section{Methods}

- Population-based historical cohort using the Discharge Abstract Database held by the Canadian Institute for Health Information.

- Included all patients 18 years or older who underwent a rectal resection for rectal cancer from April 1, 2004 - March 31, 2015 in Canada (except Quebec) with a Canadian postal address.

- Exclusion criteria: pregnancy, emergency surgery or complex multi-visceral resection.

- Provincial and national uptake of LS in rectal cancer was determined by calculating the proportion of LS cases, analysed over time.

- Factors associated with LS were determined by fitting a multiple logistic regression model.

\section{Results}

- Of 26,411 rectal cancer surgeries during the 11 years, 22,538 $(85.2 \%)$ were LS and 3,903 (14.8\%) were OS.

- Nationally, uptake of LS increased from $1.4 \%$ in 2004 to $34.7 \%$ in $2014(p<0.0001)$.

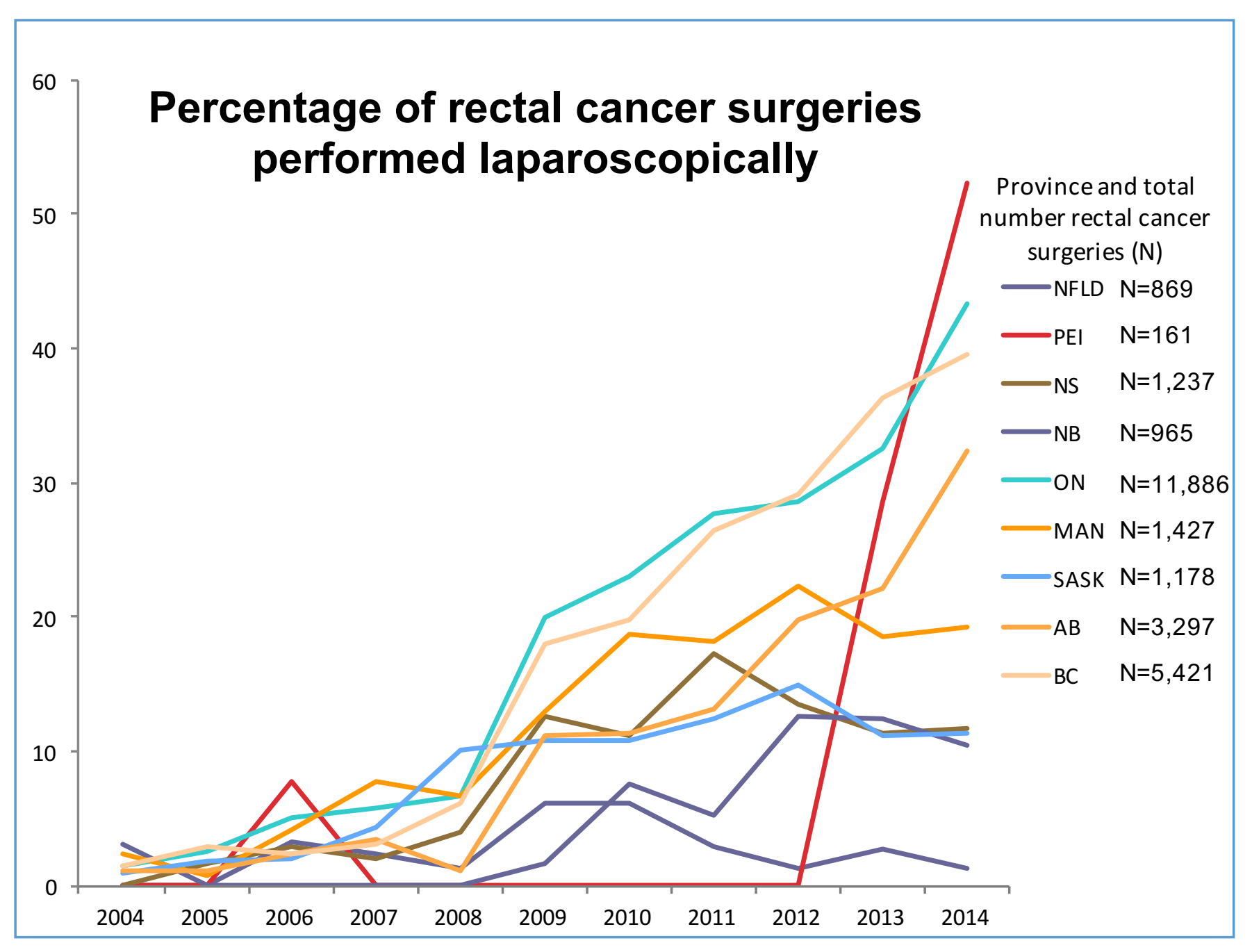

${ }^{*} p<0.0001$ for all provinces except NFLD $(p 0.3)$

Multi-variable regression of factors associated with uptake of LS

\begin{tabular}{|c|c|c|}
\hline & OR & $95 \% \mathrm{Cl}$ \\
\hline Year (per year 2004-2014) & 1.39 & $1.37-1.40$ \\
\hline Age $>65$ & 1.0 & - \\
$\leqq 65$ & 1.15 & $1.07-1.24$ \\
\hline Sex M & 1.0 & - \\
F & 1.33 & $1.24-1.44$ \\
\hline Province NL & 1.0 & - \\
PE & 4.13 & $2.12-8.05$ \\
NS & 3.50 & $2.17-5.64$ \\
ON & 1.89 & $1.12-3.18$ \\
MB & 9.29 & $6.03-14.30$ \\
SK & 5.58 & $3.52-8.85$ \\
AB & 3.47 & $2.15-5.59$ \\
BC & 4.78 & $3.07-7.44$ \\
& 8.53 & $5.52-13.18$ \\
\hline
\end{tabular}

\section{Conclusion}

- The use of LS for rectal cancer has increased markedly in Canada over the past decade.

- Significant interprovincial variation exists.

- ON, BC and PEI have experienced the greatest proportional increase in LS for rectal cancer during the study period.

PJ, Thorpe H, et al. Randomized trial of laparoscopic-assisted resection of colorectal carcinoma: 3-year results of the UK MRC CLASICC Trial Group. J Clin Oncol. 2007;25(21):3061-3068. 